\title{
Doctors within borders: meeting the health care needs of migrant farm workers in Canada
}

\author{
Michael Pysklywec MD MSc, Janet McLaughlin PhD, Michelle Tew RN, Ted Haines MD MSc
}

See related analysis article by Preibisch and Hennebry on page 1033 and at www.cmaj/cgi/doi/10.1503/cmaj.090736.

\section{The case}

José, a migrant farm worker from Mexico, presents with a one-month history of low back pain. Through broken English and Spanish, he tells you that he has been in Canada for three months working on an asparagus farm. For the past six weeks, he has been spending 10 hours per day, six days per week, bent over cutting asparagus spears. José's boss has his health card. Because José is only in town every Friday night to shop for groceries, he is not available when the radiology clinic and laboratory are open. Recognizing that his condition is related to his work, you wonder about filing a claim with the Workers' Compensation Board. José has difficulty understanding what this means, but clearly does not want his employer to know that he has a sore back. He simply wants pills to help ease the pain. He is unsure of whether he has insurance coverage for medications and wants the least expensive medicine. You write out instructions for an over-the-counter antiinflammatory medication and direct him to a pharmacy. This patient's unique circumstances have raised a number of unanswered questions.

$\mathrm{E}$ very year, thousands of migrant farm workers, particularly from Mexico and the Caribbean, come to Canada. Although they have the legal right to health care services, they present unique challenges for physicians and other health care providers related to accessibility and needs. This primer describes this population, their principal health concerns and the difficulties they face in accessing health care, and presents tools that might help in managing their care.

The term "migrant farm workers" refers to any agricultural labourers who work away from their place of permanent residence. Given that agricultural work has become less attractive to Canadians, most farm workers in Canada now come from other countries through the Temporary For- eign Worker Program run by the federal government. ${ }^{1}$ More than 27000 migrant farm workers come to Canada each year through this program. ${ }^{2}$

There are two Temporary Foreign Worker Program streams employing workers in agriculture. ${ }^{1}$ The principal stream is the Seasonal Agricultural Workers Program, a federal government initiative that employs workers from the Caribbean (most of whom are from Jamaica) and Mexico. The Seasonal Agricultural Workers Program began in 1966 and employs about 23000 workers for up to eight months annually. ${ }^{3}$

A more recent federal program, the Pilot Project for Occupations Requiring Lower Levels of Formal Training also allows for the employment of temporary foreign workers for up to two years in a variety of industries, including agriculture. There are more than 4000 agricultural workers in Canada under this program, from such countries as Guatemala, Thailand and the Philippines. There are also migrant farm workers who work without legal status or stay on past their contracts, at which point they lose status. Such unauthorized workers face unique challenges. This article focuses mainly on the experience of legally employed migrant farm workers.

Most migrant farm workers in Canada are employed in Ontario (about 17000 annually), although there are also high numbers of workers in Quebec (about 5000), British Columbia (about 3000) and Alberta (about 2000), and in pockets throughout every province. ${ }^{2}$ Men comprise the

\section{KEY POINTS}

- Every year, 25000 to 30000 migrant farm workers come to Canada.

- Most are entitled to Canadian health care benefits and workers' compensation.

- Common health issues among migrant farm workers include musculoskeletal injury, eye and skin problems, sexual health conditions and mental health concerns.

- Language-related barriers, lack of transportation, long workdays and fear of repatriation may prevent access to and use of health care services. 
vast majority, but the proportion of women has been growing in recent years to just over $4 \%$ of this population. These temporary workers are now a vital part of the economic viability of agriculture in certain parts of Canada.

Workers are recruited in their countries of origin. Most workers undergo a thorough medical examination before they enter Canada. In general, the medical examination consists of a history and physical examination, syphilis serology, HIV testing and chest radiograph. However, the requirement and nature of the examination varies by program and by country of origin. The Seasonal Agricultural Workers Program, for example, requires general fitness evaluations and chest radiographs. Citizenship and Immigration Canada requires an examination for tuberculosis from workers of some nationalities based on the tuberculosis rates of the country of origin. ${ }^{4} \mathrm{As}$ well, source countries often mandate examinations of their own citizens regardless of Canadian requirements.

Most workers stay in accommodations provided by their employers, usually on farm property, that must meet municipal building requirements. Migrant farm workers are paid at the provincial minimum or prevailing wage, whichever is higher.' They typically work long days, six or seven days per week.

The employment circumstances for migrant farm workers in Canada are precarious. Their future employment can be influenced by their employer's evaluation of them, they are not able

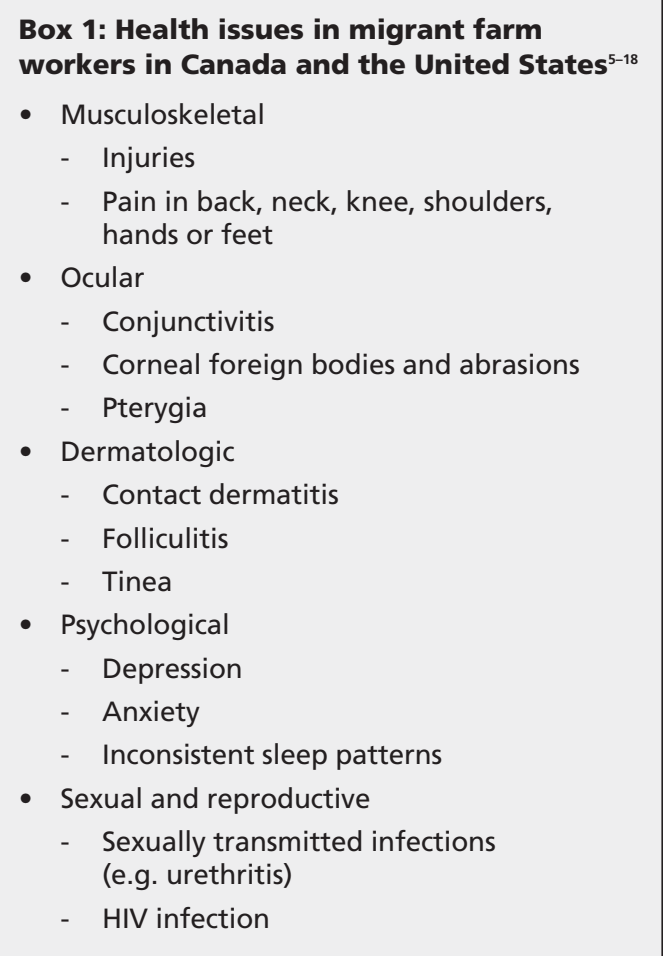

to freely change employers, and they may be fired and repatriated with little access to recourse.

\section{Coverage for health care}

All documented migrant farm workers have medical coverage in Canada, because employers must provide such coverage as a condition of employment. Each province provides workers' compensation coverage for migrant farm workers for occupational injury and illness. The type of nonoccupational coverage varies among provinces and program streams. Workers in the Seasonal Agricultural Workers Program in Ontario and Quebec are covered by provincial health insurance for the duration of their stay. Those in the Seasonal Agricultural Worker Program in other provinces and those in the Pilot Project for Occupations Requiring Lower Levels of Formal Training are covered by a blend of private and public coverage (such as in British Columbia) or by private insurance alone. They often have additional insurance coverage for medications and other medical expenses, but that is variable. They pay Canadian employment insurance premiums, pension plan premiums and income taxes.

\section{Principal health issues}

Although most of the literature on the health of migrant farm workers reports on those in the United States, there is growing literature on the experiences of migrant farm workers in Canada (Box 1). $)^{5-18}$

\section{The Canadian experience}

A qualitative study based in Ontario sought to identify the major health issues affecting migrant farm workers in Canada. ${ }^{5}$ The occupational health concerns identified in the study included musculoskeletal injury and symptoms related to exposure to pesticides and climatic extremes. Common themes included sexual and reproductive health, mental health issues and other health concerns. Poor living conditions contributed to a number of concerns, including inconsistent sleep patterns, poor nutritional practices and unsafe methods of transportation. Although few studies involving migrant farm workers have focused specifically on health, other researchers studying migrant farm workers in Canada have noted similar issues. ${ }^{6-9}$

From our experience at the Occupational Health Clinics for Ontario Workers in 2009 (Box 2), $35 \%$ of visits to the clinic by migrant workers were for musculoskeletal problems relating to their work. Ocular issues (13\% of visits) and skin issues $(6 \%)$ were also very common. Despite the clinic's focus on occupational health, patients also 
presented with sexual health concerns, primarily urethritis. Workers report that they attend the Occupational Health Clinics for Ontario Workers because we provide translators and don't require proof of medical insurance (patients are often confused about health insurance plans) or because they were referred by a coworker.

\section{The American experience}

A review of the US literature reveals numerous reports on the health of migrant farm workers. These studies tend to be descriptive, cross-sectional evaluations, presumably because of the difficulties of studying a migrant population.

Given that agricultural work is inherently high-risk and most employees' time is spent at work, occupational health issues are common among migrant farm workers. ${ }^{910}$ Surveys of such workers in the United States found a high prevalence of musculoskeletal symptoms. ${ }^{11,12} \mathrm{~A}$ survey of 425 workers in two different states reported back pain in $24 \%-39 \%$ of workers. ${ }^{11}$ Similarly, a Californian survey involving almost $1000 \mathrm{mi}-$ grant farm workers found that about $40 \%$ reported persistent pain in the back, neck, knees, shoulders, hands or feet. ${ }^{12}$ There are clear ergonomic risks in the physically demanding, repetitive tasks of agricultural labour. ${ }^{10}$

Other common occupational issues include ocular problems and dermatitis. A review ${ }^{13}$ of 35 published studies reported that typical ocular disorders included conjunctivitis, pterygia and corneal foreign bodies, while a cross-sectional survey ${ }^{11}$ reported an estimated prevalence of $35 \%$ for eye symptoms. A questionnaire and a clinical assessment of more than 450 American migrant farm workers found that contact dermatitis, folliculitis and tinea infections were common skin issues in this population, occurring in more than $30 \%$ of workers..$^{11,14}$

Most conditions involving the skin or eye among migrant farm workers are likely caused by exposure to chemical agents (e.g., pesticides) ${ }^{15}$ or irritant dusts, by physical hazards and by prolonged sun exposure inherent in their work. Migrant farm workers are particularly vulnerable to harm from exposure to pesticides because of insufficient access to and knowledge of protective measures, inadequate equipment and sanitation facilities, and poor communication with employers (Box 3). ${ }^{16}$

Mental health disorders, especially depression and anxiety, are another major issue among migrants. Qualitative studies involving 30 migrant farm workers in Ontario ${ }^{17}$ and 75 in the United States ${ }^{18}$ reported numerous themes that contributed to psychological malady, including poverty, discrimination, living and working conditions that are unpredictable, difficult or rigid, and cultural and familial dislocation.

Migrant farm workers are also at risk for sexual and reproductive ailments. Though the literature has focused on HIV infection, ${ }^{9,10}$ our clinical experience suggests that other sexually transmitted infections, such as chlamydia, are not uncommon in this group. Factors such as separation from family, lack of access to educational and preventive services, and culturally based beliefs about contraception may contribute to this problem. ${ }^{10}$

Whether migrant farm workers in Canada share the same health risks as their American counterparts is unknown. In general, migrant farm workers in the United States are more mobile, are less regulated and have more limited access to health care than those in Canada. Whereas occupationally related risks (such as musculoskeletal, ocular and skin conditions) may be similar between workers in the two countries, other risks (e.g., for infectious diseases and mental health disorders) are likely quite different, given the social differences between the countries and their programs for migrant workers. These differences emphasize the need for good quality research on the health issues of migrant farm workers from a Canadian perspective.

\section{Access to health care}

Despite having legal access to health care and other benefits in Canada, many workers find it difficult to gain access to their entitlements. Our experience caring for workers in the clinic, combined with evidence in the literature,,$^{5-10,19}$ suggests that common barriers include language differences and a lack of interpreters, problems or delays in accessing health cards or coverage, cultural differences, lack of transportation, limited education and literacy, and poor health literacy. Other barriers include long workdays, dependence on employers to access health care (including concerns about confidentiality when employers act as translators), unwillingness to take time off work for fear of losing employment or pay, and

\section{Box 2: Our experience}

To better understand the occupational health status and context of migrant farm workers, the Occupational Health Clinics for Ontario Workers has been conducting medical clinics for migrant farm workers since 2007. Each clinic is staffed by a physician, a nurse, an occupational hygienist and a coordinator, and is assisted by volunteers and interpreters from various community groups.

Clinics are held in communities in southern Ontario with a high density of migrant farm workers, usually every other Friday night (the night most workers have off) throughout the farming season, at a location near where workers are taken weekly to buy groceries.

During the summer of 2010, we had more than 150 patient visits during 11 clinics. Patients were primarily from Mexico, the Caribbean and Thailand These clinics have allowed us to provide services to this unique and interesting population and have provided us with a window into the medical and social experiences of migrant farm workers. 
fear of being repatriated when sick or injured.

Migrant workers typically access services at rural walk-in clinics and emergency departments that are already overstressed. The physician treating this population will be challenged by language barriers and cultural differences, difficulties in followup and subsequent problems with contact and compliance resulting from the barriers listed above.

In our experience, the precarious nature of the employment status of migrant farm workers has a substantial impact on how this population is managed clinically. Their physical health is directly related to their ability to work in Canada. Fears of repatriation or loss of future Canadian employment lead to an unwillingness to report injury or illness, apply for workers' compensation or follow through on treatment plans such as work modification or absence.

\section{Approaches to clinical care}

The following suggestions, which are based on our experience and a review of the literature, may help health care providers to serve this unique group.

First, clinicians should strive to be aware of and sensitive to the unique needs, circumstances and vulnerabilities of migrant workers, and to adapt their practices accordingly. For example, physicians could schedule clinic hours to coincide with times in which workers are likely to be in town, or arrange with employers for access to the workers during regular hours. Given the limited job alternatives for migrant workers and the precarious nature of their employment in Canada, clinicians may need to be flexible or creative with treatment-related work restrictions. Clinics could also develop interpretation services that are independent from workers' employers (e.g., by con-

Box 3: Possible factors contributing to health issues among migrant farm workers ${ }^{5-10,15-18}$

- Exposure to pesticides or irritant dust

- Climatic extremes, including prolonged sun exposure

- Unsafe methods of transportation

- Repetitive tasks

- Inadequate access to or knowledge of protective measures and equipment

- Inadequate access to sanitation facilities

- Unpredictable, difficult or rigid living or working conditions

- Poor communication with employers

- Poor nutritional practices

- Cultural dislocation

- Isolation and separation from family

- Discrimination necting with local support groups, translation services or bilingual volunteers) and adopt specialized resources for migrant workers, such as illustrated, multilingual patient handouts (samples available at www.migrantclinician.org).

In addition, it is helpful to maintain clinical vigilance for common health issues in this group, in recognition of the heavy physical demands of farm labour and the potential for symptoms of irritation from pesticide exposure and other hazards. Finally, clinicians could engage in discussions with local health agencies to consider additional or alternative models of health care delivery. These alternatives might include mobile services, such as a health care services bus, to take health professionals to the workers; development of specialized clinics for high-needs issues like occupational or sexual health; identification and development of specific resources in the region (e.g., seeking and engaging interested family physicians, or consultants, pharmacies or community groups able to communicate in relevant languages).

Beyond these direct interventions at the physician-patient level, there are broader systemic issues that need to be addressed. These issues include problematic access to health care and workers' compensation, job insecurity, and inadequate training and prevention services. Such issues are beyond the scope of the individual physician and will require more effective planning, coordination and response on the part of the international and Canadian agencies involved.

\section{Conclusion}

Migrant farm workers are a vulnerable group with particular risks and needs. Issues related to occupational injury and exposures in particular, but also to mental and sexual health, have been identified as areas of concern. In the face of such risks, migrant farm workers encounter many barriers to accessing health care services. Physicians working with this group should take these circumstances into account and consider partnering with relevant professionals and groups in the community to provide more accessible, appropriate and humane health care.

\section{References}

1. Temporary foreign worker program. Ottawa (ON): Human Resources and Skills Development Canada; 2010. Available: www.hrsdc.gc.ca/eng/workplaceskills/foreign_workers/index .shtml (accessed 2011 Apr. 7).

2. Citizenship and Immigration Canada. Facts and figures 2009. Ottawa (ON): Minister of Public Works and Government Services Canada; 2010.

3. Citizenship and Immigration Canada. Total entries of foreign workers by yearly sub-status. Ottawa $(\mathrm{ON})$ : Minister of Public Works and Government Services Canada, 2010. Available: www.cic.gc.ca /english/resources/statistics/facts2009/temporary/05.asp (accessed 2011 Apr. 7).

4. Citizenship and Immigration Canada. Medical examination requirements for visitors. Ottawa (ON): Minister of Public Works 
and Government Services Canada, 2010. Available: www.cic.gc .ca/english/information/medical/medexams-temp.asp (accessed 2011 Apr. 7).

5. McLaughlin J. Migration and health: implications for development. A case study of Mexican and Jamaican migrants in Canada's seasonal Agricultural Workers Program. Ottawa (ON): The Canadian Foundation for the Americas (FOCAL); 2009. Available: www.focal.ca/pdf/migration_McLaughlin_health\%20 case $\% 20$ study $\% 20$ Mexican\%20Jamaican\%20migrants\%20Canada $\% 20$ seasonal\%20agricultural\%20workers_October\%202009.pdf (accessed 2011 Apr. 7).

6. Hennebry J, Preibisch K, McLaughlin J. Health across borders - health status, risks and care among transnational migrant farm workers in Ontario. (Toronto ON): CERIS Ontario Metropolis Centre: 2010

7. Fairey D, Hanson C, MacInnes G, et al. Cultivating farmworker rights: ending the exploitation of immigrant and migrant farmworkers in BC. The Canadian Centre for Policy Alternatives, Justicia for Migrant Workers, Progressive Intercultural Community Services, and the BC Federation of Labour; 2008. Available: www.policyalternatives.ca/publications/reports/cultivating -farmworker-rights (accessed $2011 \mathrm{Apr}$. 7).

8. McLaughlin J, Hennebry JL. Backgrounder on health and safety for migrant farmworkers in Canada. Waterloo (ON): International Migration Research Centre; 2010. Available: www.wlu.ca /docsnpubs_detail.php?grp_id=2599\&doc_id=44258 (accessed 2011 Apr. 7).

9. Villarejo D. The health of U.S. hired farm workers. Annu Rev Public Health 2003;24:175-93.

10. Hansen E, Donohoe M. Health issues of migrant and seasonal farmworkers. J Health Care Poor Underserved 2003;14:153-64

11. Cameron L, Lalich N, Bauer S, et al. Occupational health survey of farm workers by camp health aides. J Agric Saf Health 2006; 12:139-53.

12. Villarejo D, McCurdy SA. The California agricultural workers health survey. J Agric Saf Health 2008;14:135-46.

13. Lacey SE, Forst LS, Petrea RE, et al. Eye injury in migrant farm workers and suggested hazard controls. J Agric Saf Health 2007; 13:259-74.

14. Krejci-Manwaring J, Schulz MR, Felman SR, et al. Skin disease among Latino farmworkers in North Carolina. J Agric Saf Health
2006;12:155-63.

15. Das R, Steege A, Baron S, et al. Pesticide-related illness among migrant farm workers in the United States. Int J Occup Environ Health 2001;7:303-12.

16. Arcury TA, Quandt SA, Cravey AJ, et al. Farmworker reports of pesticide safety and sanitation in the work environment. Am J Ind Med 2001;39:487-98

17. Mysyk A, England M, Gallegos JAA. Nerves as embodied metaphor in the Canada/Mexico seasonal agricultural workers program. Med Anthropol 2008;27:383-404.

18. Magaña CG, Hovey JD. Psychosocial stressors associated with Mexican migrant farmworkers in the midwest United States. $J$ Immigr Health 2003;5:75-86.

19. Arcury TA, Quandt SA. Delivery of health services to migrant and seasonal farmworkers. Annu Rev Public Health 2007;28:345-63.

Affiliations: From the Department of Clinical Epidemiology and Biostatistics (Pysklywec, Haines), McMaster University, Hamilton, Ont.; The International Migration Research Centre (MacLaughlin) Wilfrid Laurier University, Waterloo, Ont.; and the Occupational Health Clinics for Ontario Workers (Tew), Hamilton, Ont.

Contributors: Michael Pysklywec contributed to the literature review, conception, writing and editing of the article. Janet McLaughlin conducted much of the literature review, drafted the manuscript and contributed to the conception, writing and editing of the article. Michelle Tew contributed to the design and offered editorial comments on the manuscript. Ted Haines provided editorial comments on the manuscript. All of the authors approved the final version of the manuscript submitted for publication.

Funding: This work was supported by doctoral scholarship grants to Janet McLaughlin from the Social Sciences and Humanities Research Council of Canada and the International Development Research Centre, and by a doctoral research training fellowship to Janet McLaughlin from the Institute for Work and Health. 